\title{
Seismic behavior of interior RC beam-column joints with additional bars under cyclic loading
}

\author{
Xilin Lư ${ }^{1}$, Tonny $\mathrm{H}$. Urukap ${ }^{2}$, Sen $\mathrm{Li}^{2}$ and Fangshu Lin*2 \\ ${ }^{1}$ State Key Laboratory of Disaster Reduction in Civil Engineering, Tongji University, Shanghai, China \\ ${ }^{2}$ College of Civil Engineering, Tongji University, Shanghai, China \\ (Received April 20, 2011, Revised August 11, 2011, Accepted August 18, 2011)
}

\begin{abstract}
The behavior of beam-column joints in moment resisting frame structures is susceptible to damage caused by seismic effects due to poor performance of the joints. A good number of researches were carried out to understand the complex mechanism of RC joints considered in current seismic design codes. The traditional construction detailing of transverse reinforcement has resulted in serious joint failures during earthquakes. This paper introduces a new design philosophy involving the use of additional diagonal bars within the joint particularly suitable for low to medium seismic effects in earthquake zones. In this study, ten full-scale interior beam-column specimens were constructed with various additional reinforcement details and configurations. The results of the experiment showed that adding additional bars is a promising approach in reinforced concrete structures where earthquakes are eminent. In terms of overall cracking observation during the test, the specimens with additional bars (diagonal and straight) compared with the ones without them showed fewer cracks in the column. Furthermore, concrete confinement is certainly an important design measure as recommended by most international codes.
\end{abstract}

Keywords: reversed cyclic loading; beam-column joint; plastic hinge; additional diagonal bars; displacement ductility; column shear force; crack propagation

\section{Introduction}

Most recent earthquakes like in Wenchuan (2008) and Chi-Chi, Taiwan (1999) resulted in greater damages beyond prediction at the joints. Most of the observed structural failure has been initiated by a damage or failure in the beam-column joint as known from literature (Cheung et al. 1993). This obviously warned engineers and researchers of the importance of joints which has to be taken seriously into account during design phase in earthquake zones.

Through the lessons learnt from past earthquakes and experimental researches, engineers recognize that the seismic resistance of a RC structure depends on how well its structural members have been detailed. In due respect to design philosophy descriptions (Nawy 2005), this paper puts emphasis strictly on reinforced concrete structures as the main objective.

The poor design practice of RC beam-column joint is compounded by the high demand imposed by the adjourning flexural members (beam and columns) in the event of mobilizing their inelastic capacities to dissipate seismic energy. Numerous researches have been carried out over the past few

\footnotetext{
* Corresponding author, Ph. D. Candidate, E-mail: fangshulin16@gmail.com
} 
decades, which are described in literatures (MacGregor 1988, Nelson et al. 2004, Park and Pauley 1975) to understand the complex mechanism and to study the behavior of joints under seismic loadings experimentally and analytically.

The detailing of beam-column joints of RC frame structures in regions of high earthquake risk is normally governed by code provisions (GB 50010-2002, ACI 318-05, NZS 3101 1995, EC8 2003) that require a considerable amount of transverse reinforcement to resist the horizontal joint shear forces. In recent years, a lot of non-conventional methods have been developed to improve the performance of RC beam-column joints under seismic loading, such as the joints with fiberreinforced polymer (FRP) (Thermou and Elnashai 2006, Ghobarah and Said 2001, Karayannis and Sirkelis 2002, Karayannis and Sirkelis 2008), RC jackets (Karayannis et al. 2006, Karayannis et al. 2008) and inclined bars (Au et al. 2005, Chalioris et al. 2007, Chalioris et al. 2008, Bindhu et al. 2008), etc.

This paper focuses on the design of interior beam-column joints with additional bars of different sizes and configurations. Ten full-scale specimens were tested and the detailing has been shown to be effective in improving the seismic resistance of joints. Initial findings on the use of crossdiagonal reinforcement in interior beam-column joints have been rather promising (Pam et al. 2002).

\section{Characteristic behavior of interior beam-column joint under lateral loading}

The behavior characteristics of joints due to factored lateral loadings (seismic loading) are quite unique and serious in seismic regions unlike joints designed only for vertical loadings (gravity loading). Most international codes (GB 50010-2002, ACI 318-05, NZS 3101 1995, EC8 2003) specify standards, design factors and design formulae particularly for moment resisting frames under seismic loading. Though various codes attempt to explain the design of joint, little attention was given to the design of reinforced concrete structures. It appears that after the evaluation of working stresses in adjacent members, most designers normally assume that conditions within the joint, which often have somewhat larger dimensions than the members it joined, were not critical. The gradual adoption of the philosophy of limit stage design has exposed the weakness of this assumption. The truth is, joints are often the weakest link in a structural system due to seismic loadings.

The structural demand on joints is greatly affected by the type of loading system and loading path in any type of joint (interior, exterior or corner). Therefore, it is of certain importance to use design procedures in which the severity of each type of loading is properly recognized. For instance, strength under monotonic loading without stress reversals will be the design criterion for continuous reinforced concrete structures subjected to gravity loading only. In other cases, both strength and ductility of the adjoining members under reversed loading will govern the design of joints, like a rigid jointed multistory frame under seismic loading. A large amount of joint reinforcement can be expected for the second case because strength degradation of the concrete under repeated reversal loading will occur.

\subsection{Strong column - weak beam concept}

Unlike, design for gravity, seismic design philosophy (Cheung et al. 1993) puts emphasis on 
accommodating enough ductility at the joints so that the whole structural frame will be able to dissipate lateral forces (seismic loading). It is vital that, ductility of main structural frame comes from structural members, particularly the beam and column. The joint undergoes inelastic rotations as the ductility capacity of the entire members is transferred to the joint. In reinforced concrete structural members, the inelastic rotations spread over certain regions. These actions of force effects are named as the plastic hinges or plastic hinging. During these inelastic deformations, the actual material properties of $\mathrm{RC}$ beams and columns are beyond elastic range, thus damages at the joints are obviously noticeable. The plastic hinges are expected locations where the structural damages can be allowed to occur due to inelastic actions involving large deformations. Therefore, it is very important in seismic design that the damages in the form of plastic hinges are accepted to be formed in beams rather than in columns.

The strong-column weak-beam concept is enforced in ACI 352R-02 (2002) through Sect. 21.4.2.2, which states that the flexural strength of columns should be $6 / 5$ of that of the adjoining beams, as indicated below.

$$
\sum M_{n c} \geq 1.2 \sum M_{n b}
$$

where $\sum M_{n c}$ is the sum of nominal flexural strengths of the columns framing into the joint, computed at the faces of the joint under factored axial forces such that they give the lowest flexural strength.

\subsection{Interior beam-column joint}

Most failure of reinforced concrete structures occurs because of insufficient attention given to the detailing of the joint. The beam-column joint is defined as the portion of the column within the depth of the beam that frames into it (MacGregor 1988). Other failures may also result in inadequacies of structural members. The functional requirement of a joint, which is the zone of intersection of beams and columns, is to enable the adjourning members to develop and sustain their ultimate capacity (Nelson et al. 2004). The requirement for joint design has been always serious particularly under seismic loading. The joints should have adequate strength and stiffness to resist the internal forces induced by the framing members. Joint is of great importance, as all forces that occur at the ends of the members must be transmitted through the joint to the supporting members. These forces develop complex stresses at the junction of beam and column joints.

The behavior of forces developed at the joint vicinity corresponds to detailing and geometry configuration of the joint itself as well as various forces transferred to the joint. The forces experienced in all three types of joints differ from one to another. The resultant forces due to seismic loading at these joints are elaborated in latter in terms of stresses and crack propagation associated thereof (MayField et al. 1971).

The high internal forces developed at plastic hinges cause critical bond conditions in the longitudinal reinforcing bars passing through the joint and also impose high shear demand in the joint core. In a recent experimental research, it was noted that the joint loading behavior showed an extremely complex interaction between shear and bond (ACI Committee 408 1970). The bond requirements of the longitudinal reinforcement bars in reinforced concrete beam-column joint have greater impacts on the shear resisting mechanism behavior to a certain limit.

In an interior joint, the stresses prolonging simultaneously throughout the joint alter from 
compression to tension. This generates a push-pull effect that emphasizes greater demand on bond strength and provides sufficient development length within the joint core. The development length has to satisfy compression and tension force requirements in the same longitudinal reinforcement bar. Insufficient development length and the spread of splitting cracks in the joint core may result in slippage of bars. Leon (1990), observed that when the development length was higher than 28 diameters, obtained lower or no bond degradation with respect to various shear stress levels in the joint.

The diagonal concrete strut action mechanism (MacGregor 1988, Nelson et al. 2004, Park and Pauley 1975) is formed by the major diagonal concrete compression force in the joint. This force is produced by the vertical and horizontal compression stresses as well as critical section of shear stresses on concrete of the beam and column. The truss mechanism (MacGregor 1988, Nelson et al. 2004, Park and Pauley 1975) is formed by a combination of the bond stress transfer along the beam and column longitudinal reinforcement, the tensile resistance of lateral reinforcement and compression resistance of uniform diagonal concrete struts in the joint panel. The strength of the strut mechanism depends on the comprehensive strength of concrete and that of the truss mechanism on the tensile yield strength of the lateral reinforcement crossing the failure plane.

In resisting the joint shear, the diagonal strut mechanism can exist without any bond stress transfer along the beam and column reinforcement within the joint, while the truss mechanism can develop only when a good bond transfer is maintained along the beam and column reinforcement.

In recent years, researchers developed different methods in order to predict the shear strength in various types of $\mathrm{RC}$ joints more accurately. Some researchers proposed mathematical models to predict joint shear strength (Hwang and Lee 1999, 2000, Attaalla 2004), while some introduced methodologies to construct joint shear strength models for RC joints (Kim et al. 2007).

\section{Experimental research}

The experimental research investigated the seismic behavior of typical interior beam-column joint subassemblies under simulated cyclic loading patterns. Comparisons of conventional concrete joints, additional diagonal bars along beams, additional diagonal bars along columns and additional straight bars along column were investigated after having ten specimens tested. Ten full-scale test specimens were fabricated primarily based on strong-column weak-beam concept as discussed previously.

In particular, the parameters studied in these tests were the joint critical principal strength, ductility, joint behavior and energy dissipation capacity. The first four conventional seismic beamcolumn joints reinforced with various steel contents in the joint region were tested to examine the contribution of longitudinal reinforcement in the beam affecting the joint shear resistance capacity. These tests gave reasonable behavioral information on the flexural behavior mechanism at plastic hinge region as well as the seismic behavior of the joint mechanism and damages under extreme reversal loadings.

\subsection{Details of test specimens}

All test specimens (Fig. 1) have common beam sizes of $250 \mathrm{~mm}$ in width by $400 \mathrm{~mm}$ in depth, column cross-sectional area of $400 \mathrm{~mm} \times 400 \mathrm{~mm}$ as well as common overall length measured $3500 \mathrm{~mm}$ for both beams and columns. The Beam-Column Joint test specimens are grouped into 
four as described below.

Group I, the conventional seismic design practice according to Chinese Code and are named as J1-1, J1-2, J1-3 and J1-4. Joint J1-2, J1-3 and J1-4 have the same principle of detailing, however, the number of longitudinal reinforcements changed from 4 (J1-1) to 3 with differing sizes of $20 \mathrm{~mm}, 22 \mathrm{~mm}$ and $25 \mathrm{~mm}$ respectively.

Group II, new design with respect to seismic design code provisions and are named as J2-1, J2-2 and J2-3. This new design group has the same vertical and horizontal reinforcement bars as J1-1 and has additional diagonal bars along the column within the joint region. The additional reinforcement bars overlap approximately $400 \mathrm{~mm}$ towards the column end from the top longitudinal bars in the beam. In detail, test specimen J2-1 and J2-3 were set to be without stirrups at the beam-column joint region. Obvious difference between these test frames was the diameter of
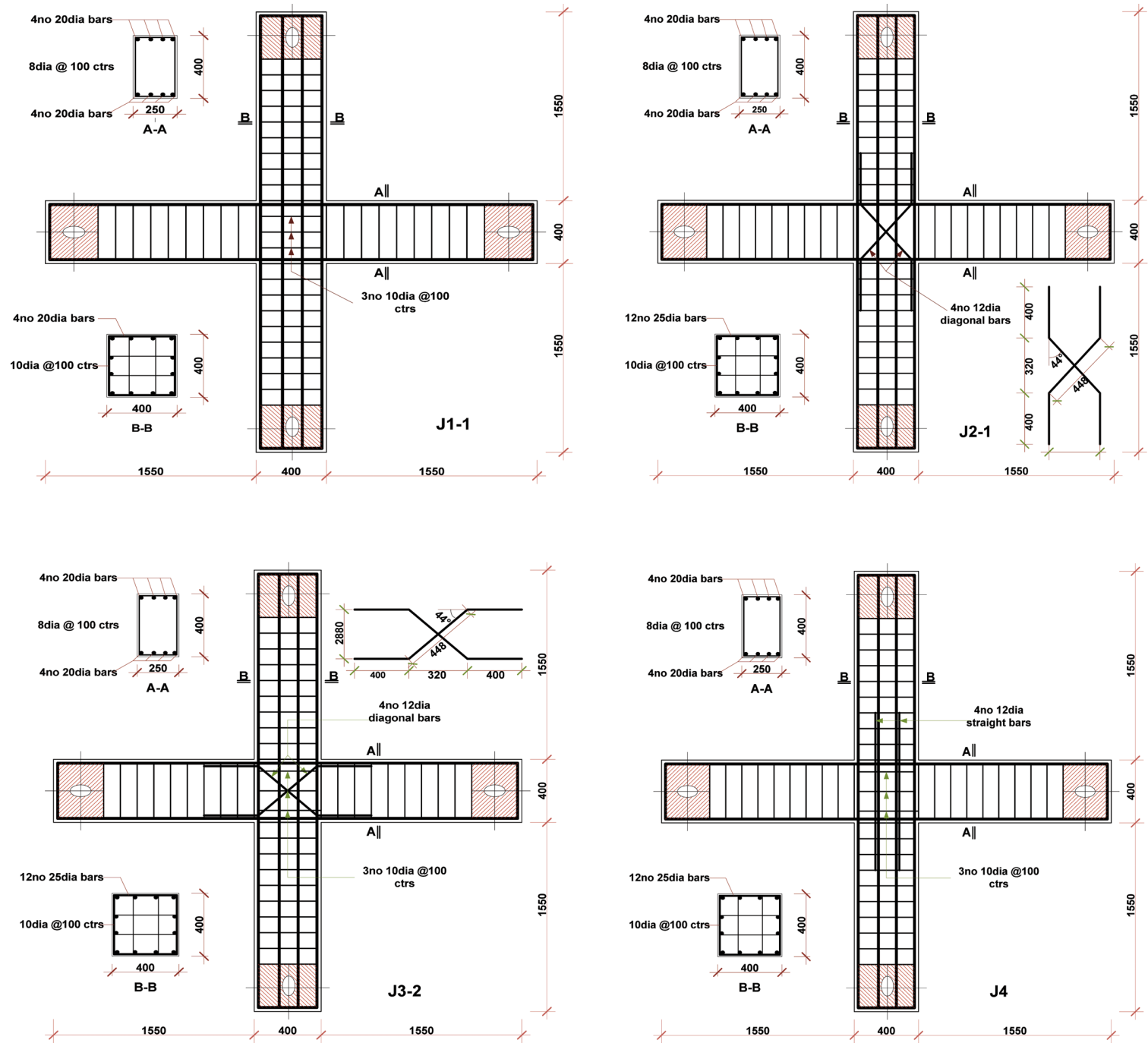

Fig. 1 Sample design and detailing of test specimens. J1-1 (Group I), J2-1 (Group II), J3-2 (Group III) and J4 (Group IV) 
the diagonal additional bars, that is, $12 \mathrm{~mm}$ in diameter for $\mathrm{J} 2-1$ and $16 \mathrm{~mm}$ in diameter for $\mathrm{J} 2-3$.

Group III, new design as in (b) with different reinforcement configurations and are named as J3-1 and J3-2. Group III is another new design having the same details as in J2-1, but this time, the diagonal additional reinforcement bars were fixed along the beam instead of column. J3-1 was designed only with $12 \mathrm{~mm}$ in diameter additional bars while J3-2 with additional diagonal bars of the same size and $10 \mathrm{~mm}$ stirrups within the joint region. Strength of beam closer to the joint core increased by some percent due to elongation of additional bar ends away from the joint yet the test detail was to examine joint behavior with this kind of reinforcement arrangement under lateral loading.

Group IV, is named as J4. Joint J4-1 is the only test frame in this group. The horizontal and vertical bars are of the same as J1-1, Group II and Group III. Nevertheless, the joint region has three $10 \mathrm{~mm}$ in diameter round plain stirrups and additional straight deformed bars of $12 \mathrm{~mm}$ in diameter fixed at the central vertical reinforcement bars of the column on opposite faces. The additional straight deformed bars overlap about $400 \mathrm{~mm}$ away from the joint region towards the column ends.

\subsection{Material specifications}

All the ten specimens were prefabricated from commercial ready-mixed concrete. Conventional concrete of specified characteristic cube strength of standard Chinese C30 $\left(f_{c k}=14.3 \mathrm{~N} / \mathrm{mm}^{2}\right)$ for beams and $\mathrm{C} 40\left(f_{c k}=19.1 \mathrm{~N} / \mathrm{mm}^{2}\right)$ for columns were used in the construction of the joint specimens. The focus of this research was on the reinforcement content and arrangements in the joint region. Thus, the concrete specifications used in construction of all specimens were identical, that is, C40 concrete for the column and C30 concrete for the beam as traditionally used in the architecture and construction industry. Compliance test cube $(150 \mathrm{~mm} \times 150 \mathrm{~mm} \times 150 \mathrm{~mm})$ and prism $(100 \mathrm{~mm} \times$ $100 \mathrm{~mm} \times 300 \mathrm{~mm}$ ) specimens were collected upon each batch of concrete delivered by the supplier.

Cube test specimens were tested under compression after 28 days of curing as recommended by Code provisions and force measurements were taken when the first visible crack developed. Table 1 shows the test results of the concrete mechanical properties.

High yield deformed steel reinforcement bars of $25 \mathrm{~mm}$ in diameter were used in all specimens for the columns. While all beams had $20 \mathrm{~mm}$ diameter reinforcement bars, apart from J1-3 and J1-4 of Group I which had $22 \mathrm{~mm}$ and $25 \mathrm{~mm}$ diameter reinforcement respectively. The reinforcements are of high yield deformed bars of yield strength HRB335 $\left(f_{y}=f_{y}^{\prime}=300 \mathrm{~N} / \mathrm{mm}^{2}\right)$ specified under Chinese Code. For clarification, the reinforcement details are given in Table 2 for all test frame members. These calculations were hereto performed by code provisions, for minimum requirement

Table 1 Properties of concrete (Average test results)

\begin{tabular}{clcc}
\hline \hline Group No. & \multicolumn{1}{c}{ Properties } & Beam (C30) & Column (C40) \\
\hline \multirow{6}{*}{ I } & Compressive Strength $f_{c k}\left(\mathrm{~N} / \mathrm{mm}^{2}\right)$ & 21.4 & 35.4 \\
& Tensile Strength $f_{t k}\left(\mathrm{~N} / \mathrm{mm}^{2}\right)$ & 2.08 & 2.74 \\
& Young's Modulus $E_{c}\left(\mathrm{~N} / \mathrm{mm}^{2}\right)$ & $3.04 \times 10^{4}$ & $3.50 \times 10^{4}$ \\
\multirow{4}{*}{ II III IV IV } & Compressive Strength $f_{c k}\left(\mathrm{~N} / \mathrm{mm}^{2}\right)$ & 34.7 & 40.0 \\
& Tensile Strength $f_{t k}\left(\mathrm{~N} / \mathrm{mm}^{2}\right)$ & 2.71 & 2.93 \\
& Young's Modulus $E_{c}\left(\mathrm{~N} / \mathrm{mm}^{2}\right)$ & $3.48 \times 10^{4}$ & $3.60 \times 10^{4}$ \\
\hline
\end{tabular}


ratio $\left(0.2145\left(h / h_{o}\right)\right)$, of the GB 50011-02 code.

The stirrups used were of yield strength HPB235 $\left(f_{y}=f_{y}^{\prime}=210 \mathrm{~N} / \mathrm{mm}^{2}\right)$ for both beam and column. In detail, $8 \mathrm{~mm}$ diameter plain round steel bars were used in the beam and $10 \mathrm{~mm}$ diameter round bars were used in the column. The design of stirrups was made corresponding to Chinese code (GB 50010-2002) for minimum rectangular confinement reinforcement, $\rho_{s v}$ min, as

$$
\rho_{s v \min }=\lambda_{v} \frac{f_{c}}{f_{y}}
$$

in which $\lambda_{v}$ is the minimum confining reinforcement characteristic values according to Chinese code (GB 50010-2002). In this case, $\lambda_{v}$ equals to 0.1 based on Table 11.4.17 in GB 50010-2002.

As conventional, the stirrups closer to the joint region were spaced at $100 \mathrm{~mm}$ and $150 \mathrm{~mm}$ to the rest of beam length.

Table 3 gives the reinforcement details for additional diagonal bars and stirrups placed within the joint region. High yield deformed bars were used, $16 \mathrm{~mm}$ deformed bars were used for J2-3 while the rest of Group II to Group IV had $12 \mathrm{~mm}$ diameter bars. From earlier research (ACI 352R-02 2002), joints with diagonal bars had reasonable resisting shear strength and thus the equivalent reinforcement area required were taken to be $70 \%$ of that of nominal transverse reinforcement. Thus an equation was derived to evaluate steel ratio provided by the additional diagonal bars given as, $2 A_{s d} \cos \theta=0.7 A_{s h}$, where, $A_{s d}$ is the total area of diagonal steel bars in one direction and $A_{s h}$ is the cross-sectional area of transverse reinforcement bars in the joint. However, this is not taken into consideration due to other different arrangement and detailing of steel within the joint.

Table 2 Details of reinforcement in beams and columns

\begin{tabular}{|c|c|c|c|c|c|c|c|c|c|c|}
\hline \multirow{2}{*}{ Details } & \multicolumn{4}{|c|}{ Group I } & \multicolumn{3}{|c|}{ Group II } & \multicolumn{2}{|c|}{ Group III } & \multirow{2}{*}{$\frac{\text { Group IV }}{\mathrm{J} 4}$} \\
\hline & $\mathrm{J} 1-1$ & $\mathrm{~J} 1-2$ & $\mathrm{~J} 1-3$ & J1-4 & $\mathrm{J} 2-1$ & $\mathrm{~J} 2-2$ & $\mathrm{~J} 2-3$ & J3-1 & $\mathrm{J} 3-2$ & \\
\hline Beam & $250 \times 400$ & $250 \times 400$ & $250 \times 400$ & $250 \times 400$ & $250 \times 400$ & $250 \times 400$ & $250 \times 400$ & $250 \times 400$ & $250 \times 400$ & $250 \times 400$ \\
\hline Rebar & $8 \Phi 20$ & $6 \Phi 20$ & $6 \Phi 22$ & $6 \Phi 25$ & $8 \Phi 20$ & $8 \Phi 20$ & $8 \Phi 20$ & $8 \Phi 20$ & $8 \Phi 20$ & $8 \Phi 20$ \\
\hline $\begin{array}{c}\text { Rebar } \\
\text { Ratio (\%) }\end{array}$ & 1.4 & 1.05 & 1.27 & 1.65 & 1.4 & 1.4 & 1.4 & 1.4 & 1.4 & 1.4 \\
\hline Stirrups & ф8@100 & ф8@100 & ф8@100 & ф8@100 & ф8@100 & ф8@100 & ф8@100 & ф8@100 & ф8@100 & ф8@100 \\
\hline Column & $400 \times 400$ & $400 \times 400$ & $400 \times 400$ & $400 \times 400$ & $400 \times 400$ & $400 \times 400$ & $400 \times 400$ & $400 \times 400$ & $400 \times 400$ & $400 \times 400$ \\
\hline Rebar & $12 \Phi 25$ & $12 \Phi 25$ & $12 \Phi 25$ & $12 \Phi 25$ & $12 \Phi 25$ & $12 \Phi 25$ & $12 \Phi 25$ & $12 \Phi 25$ & $12 \Phi 25$ & $12 \Phi 25$ \\
\hline Stirrups & $\phi 10 @ 100$ & $\phi 10 @ 100$ & $\phi 10 @ 100$ & $\phi 10 @ 100$ & $\phi 10 @ 100$ & $\phi 10 @ 100$ & $\phi 10 @ 100$ & $\phi 10 @ 100$ & $\phi 10 @ 100$ & $\phi 10 @ 100$ \\
\hline
\end{tabular}

Table 3 Details of additional bars and stirrups within the joint region

\begin{tabular}{ccccccccccc}
\hline \hline \multirow{2}{*}{ Details } & \multicolumn{4}{c}{ Group I } & \multicolumn{3}{c}{ Group II } & \multicolumn{2}{c}{ Group III } & Group IV \\
\cline { 2 - 11 } & J1-1 & J1-2 & J1-3 & J1-4 & J2-1 & J2-2 & J2-3 & J3-1 & J3-2 & J4 \\
\hline Additional & None & None & None & None & $4 \Phi 12$ & $4 \Phi 12$ & $4 \Phi 16$ & $4 \Phi 12$ & $4 \Phi 12$ & $4 \Phi 12$ \\
Bars & & & & & & & & & & \\
Stirrups & $3 \phi 10 @$ & $3 \phi 10 @$ & $3 \phi 10 @$ & $3 \phi 10 @$ & None & $3 \phi 10 @$ & None & None & $3 \phi 10 @$ & $3 \phi 10 @$ \\
& 100 & 100 & 100 & 100 & & 100 & & & 100 & 100 \\
Volumetric & 1.75 & 1.75 & 1.75 & 1.75 & 0 & 1.75 & 0 & 0 & 1.75 & 1.75 \\
Ratio of & & & & & & & & & & \\
Stirrups & & & & & & & & & & \\
\hline
\end{tabular}




\subsection{Test set-up and instrumentation}

Fig. 2 shows the standard seismic joint test set up designed by College of Civil Engineering of Tongji Universtiy. The frame is made of steel in a rectangle pattern and is fixed to the floor slab. All corners are pinned joint with two axis plane of movements, that is, $x$ and $z$ plane.

The specimens were supported in vertical position and were free to move in horizontal direction either ways. An axial load of $200 \mathrm{kN}$ was exerted at the top of the column with a heavy duty hydraulic jack, thus ensuring adequate stiffness capacity as well as providing moments in the joint. A servo-controlled hydraulic actuator of $12000 \mathrm{kN}$ was used to apply the load as depicted in Fig. 2.

The beam ends were supported by horizontal rollers, while the ends were universally pinned. The steel frame was designed and constructed in order to avoid eccentric loading in the out-of-plane direction. Horizontal cyclic load was applied by displacement ductility control $\left(\Delta_{y}\right)$ with the horizontal actuator.

The system and equipments adopted in this experiment was the Mechanical Testing System (MTS) that is designed for variety of structural and vibration testing applications. The testing equipments comprise of a Micro-Console and its associated AC and/or DC controllers, an oscilloscope (in the form of an LVDT), two hydraulic actuators (Fig. 2), hydraulic service manifold (HSM) and a hydraulic power supply (HPS).

The MTS equipments were advanced and mounted adequately to provide required seismic loading and strain reading according to university test standards of Tongji University.

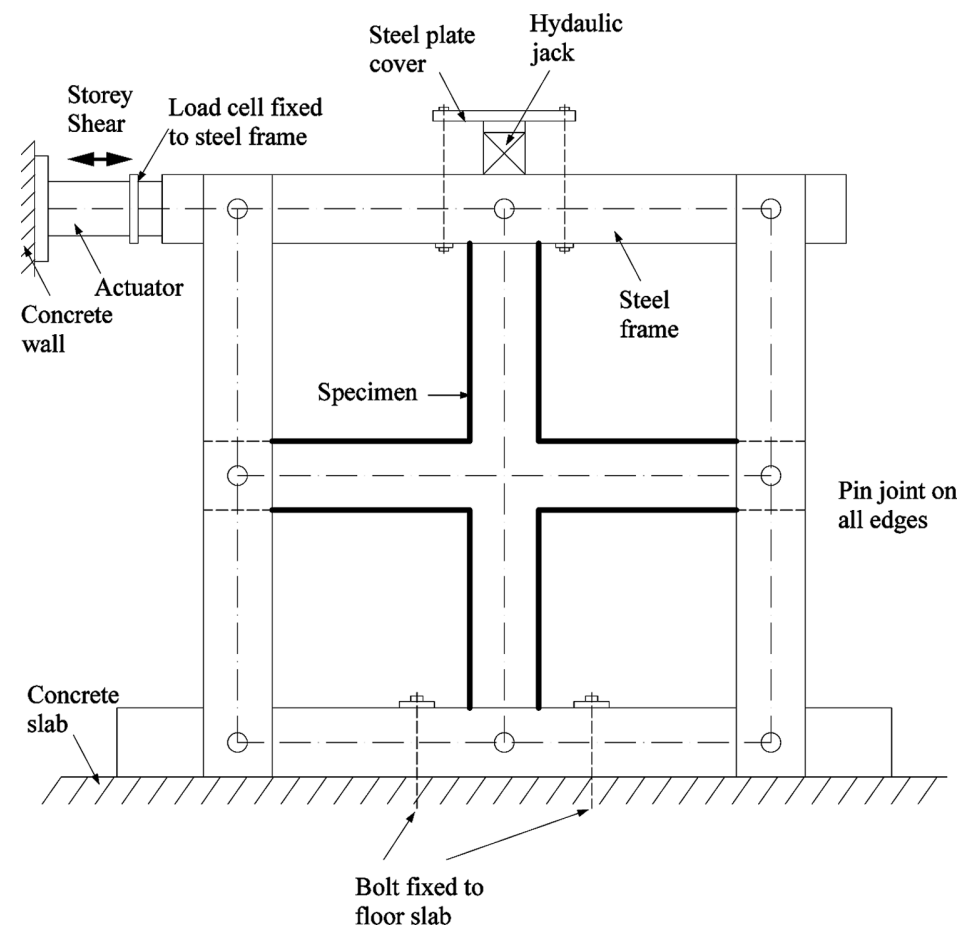

Fig. 2 Schematic representation of experiment setup 


\subsection{Loading and test procedures}

The design of beam-column frame entirely based on GB 50010-2002, however other code provisions were taken note of as would be given. Table 4 shows some details of loads and design calculations.

Joint strength coefficient is the ratio of joint shear capacity to the joint shear derived from the yield moment of the beam end. $M_{u c} / M_{u b}$ is column-to-beam strength ratio.

The test units were loaded by hydraulic load to the top of the column to simulate the building gravity load, but no 'P- $\Delta$ effect' was taken into account. By reversing the direction of the lateral loads applied to the column, the effects of earthquake loading were simulated and the applied lateral column loads induced reactive shear at the ends of the beam.

For all the tests on the interior beam-column joint units, similar loading history was used. Gradually increasing reversed cyclic displacement was applied laterally to the top of the column, with the displacement increment of $2 \mathrm{~mm}\left(\Delta_{v}, 2 \Delta_{v}, 3 \Delta_{v}, 4 \Delta_{v}\right.$ etc. $)$ and after reaching the yield strength of the longitudinal rebar in the beam, the displacement increment changed to $2 \Delta_{y} \max , 3 \Delta_{y} \max$, $4 \Delta_{y} \max$, etc. (where $\Delta_{y \max }$ is the displacement when yielding starts), until failure.

The load-history shown in Fig. 3 demonstrates the displacement and drift for each cycle. Identical Loading procedure was considered in all specimens; however slight changes were taken in controlling the joint shear strength. Initially, single cyclic loading was applied until approaching

Table 4 Details of loads and design calculations

\begin{tabular}{|c|c|c|c|c|c|c|c|c|c|c|}
\hline \multirow{2}{*}{ Details } & \multicolumn{4}{|c|}{ Group I } & \multicolumn{3}{|c|}{ Group II } & \multicolumn{2}{|c|}{ Group III } & \multirow{2}{*}{$\frac{\text { Group IV }}{\mathrm{J} 4}$} \\
\hline & $\mathrm{J} 1-1$ & $\mathrm{~J} 1-2$ & $\mathrm{~J} 1-3$ & $\mathrm{~J} 1-4$ & $\mathrm{~J} 2-1$ & $\mathrm{~J} 2-2$ & $\mathrm{~J} 2-3$ & J3-1 & $\mathrm{J} 3-2$ & \\
\hline $\begin{array}{l}\text { Joint Strength } \\
\text { Coeff } \cdot \eta \mathrm{cb}\end{array}$ & 0.86 & 1.15 & 0.95 & 0.73 & 0.55 & 0.55 & 0.86 & 0.55 & 0.86 & 0.86 \\
\hline $\begin{array}{l}\text { Moment at Beam } \\
\text { Ends }(\mathrm{kN} / \mathrm{m})\end{array}$ & 120.58 & 90.43 & 108.76 & 138.76 & 120.58 & 120.58 & 120.58 & 120.58 & 120.58 & 120.58 \\
\hline Muc/Mub & 1.53 & 2.05 & 1.7 & 1.33 & 1.53 & 1.53 & 1.53 & 1.53 & 1.53 & 1.53 \\
\hline $\begin{array}{l}\text { Axial compressive } \\
\text { force }(\mathrm{kN})\end{array}$ & 200 & 200 & 200 & 200 & 200 & 200 & 200 & 200 & 200 & 200 \\
\hline
\end{tabular}

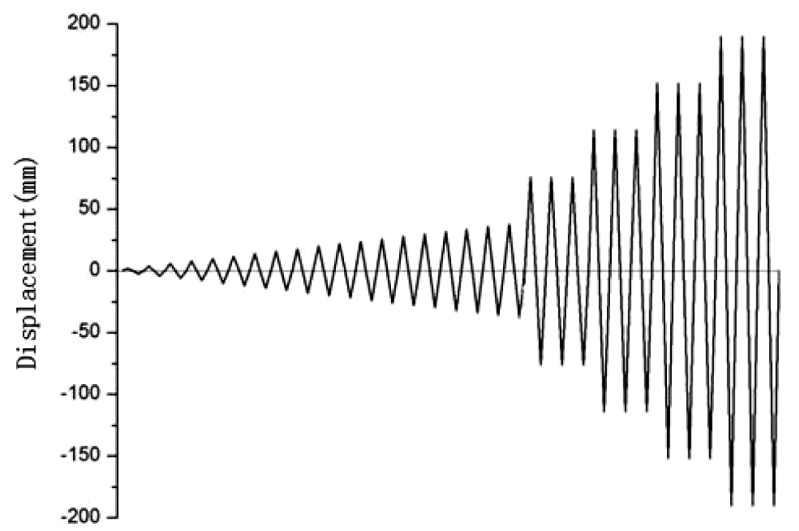

Fig. 3 Loading history 
shear strength and considering the joint was under elastic zone. During each loading cycle run, the displacements at the top of the column were recorded on a personal computer until reaching the target displacement level. After yielding started, loading cycles were made three times (twice for Group I) per displacement.

During the loading cycles corresponding storey drift, the widths of cracks were measured by surface LDs and visual observation of crack developments followed by photo shots. All cracks were marked on the white painted surface and will be discussed later.

\section{Results and discussions}

\subsection{General visual observations}

Generally speaking, cracking occurred in concrete of test specimen when the stresses reached the tensile strength $\left(f_{c t}\right)$ of concrete. Due to factored seismic loading the joint frame experienced a sagging moment and a hogging moment, resulting in opening and closing mechanical stresses on opposite edges perpendicular to each other. At minimum storey drift, most specimens showed no cracks or few minor micro-cracks, however, cracks were very obvious after reaching around $70 \%$ of joint shear strength. At maximum displacement most cracks were brittle and concrete spalled off from both beam and column in the joint region.

\section{Group I}

The cracks developed in Group I (Fig. 4(a) Fig. 4(d)) specimens spread across the joint surface and the beam. The first visible cracks developed at the center of the joint core diagonally towards compression and tension zones and diagonal cracks at the beam member also towards the joint region. It was assumed that, there was somewhat fair strength both in the joint as well as in the beam. The failure of the specimens was preceded by crushing of the joint concrete and dramatic loss of stiffness and shear distortion (deformation).

In Group I joint specimens, the cracks observed for J1-1 and J1-4 were partially similar. These joints propagate the same crack patterns but differ in extreme lateral loadings. The beam hinging mechanism under study occurred much more obvious to J1-1 than J1-4. In J1-1, cracks were greater in the beam than in the joint region. While, in J1-4, the cracks spread across both joint and the beam members, which showed equal distribution of shear stresses over the joint and frame members. This is surely, not expectable mechanical behavior in seismic design practice.

J1-2 and J1-3 differ in crack than that of J1-1 and J1-4. By decreasing longitudinal steel ratio, the beam starts to crack resulting in bending failure. The phenomenon, assumed to result in failure of structures at minimum seismic loading. The strength of beam is weaker than required for seismic loading while compared to column. The beams supposed to provide enough flexural strength in regards to strength of the columns.

With the increase of the ratio of bending moment of column to beam, the plastic hinges are more likely to develop in the beam, and the ductility of the joint improves. Furthermore, the conventional design practice (J1-1) is proven to be accurate by experimenting Group I test specimen frames.

\section{Group II}

Group II has the same longitudinal reinforcement bars in the beam and column but varied in 


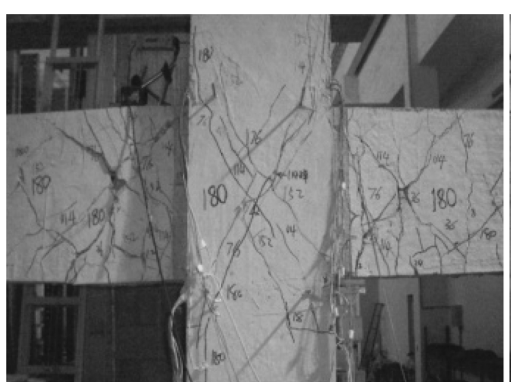

(a) J1-1, displacement: $190 \mathrm{~mm}$

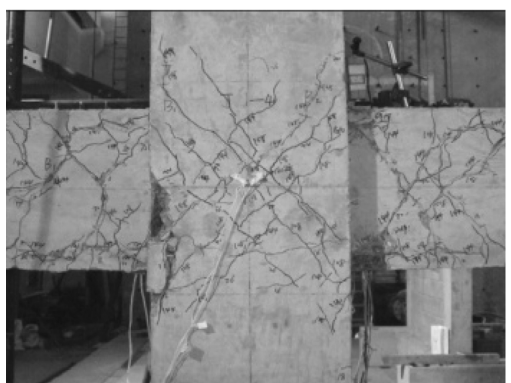

(d) J1-4, displacement: $180 \mathrm{~mm}$

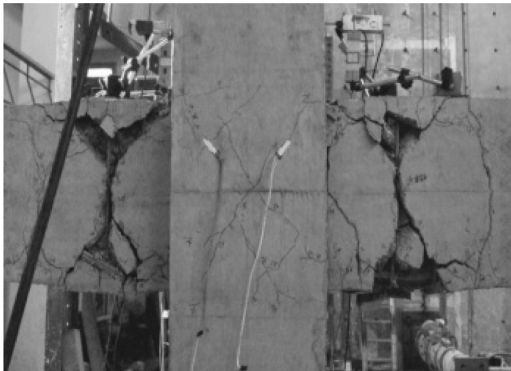

(b) J1-2, displacement: $156 \mathrm{~mm}$

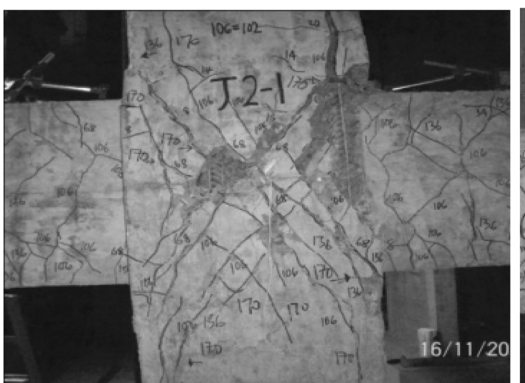

(e) J2-1, displacement: $190 \mathrm{~mm}$

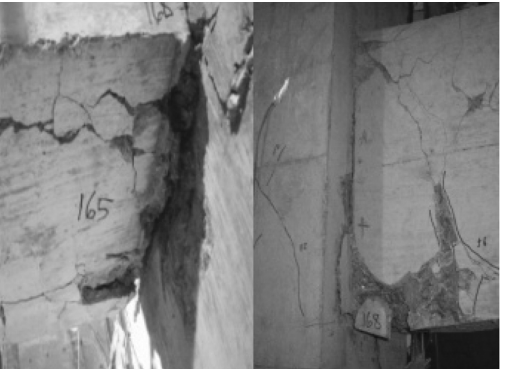

(c) J1-3, displacement: $168 \mathrm{~mm}$

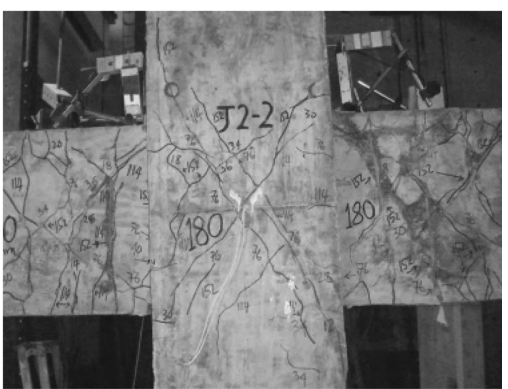

(f) J2-2, displacement: $180 \mathrm{~mm}$

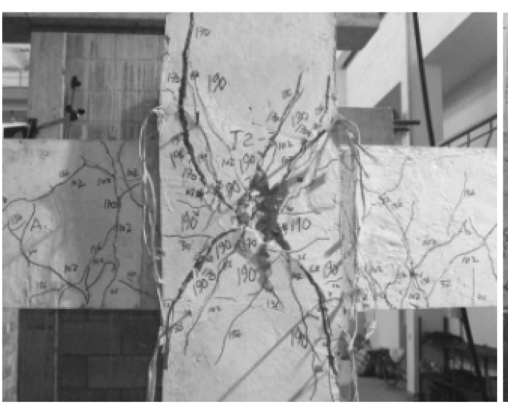

(g) J2-3, displacement: $190 \mathrm{~mm}$

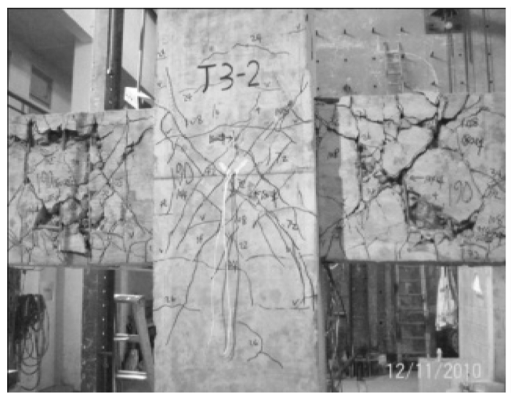

(i) J3-2, displacement: $190 \mathrm{~mm}$

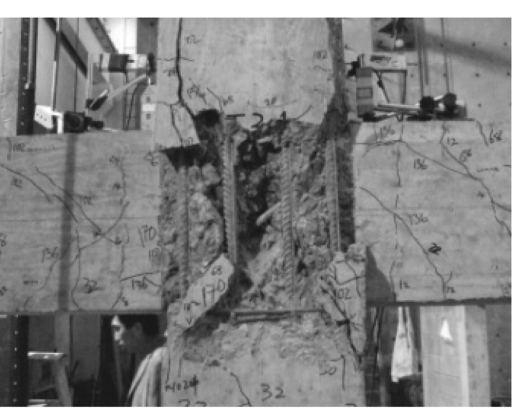

(h) J3-1, displacement: $190 \mathrm{~mm}$

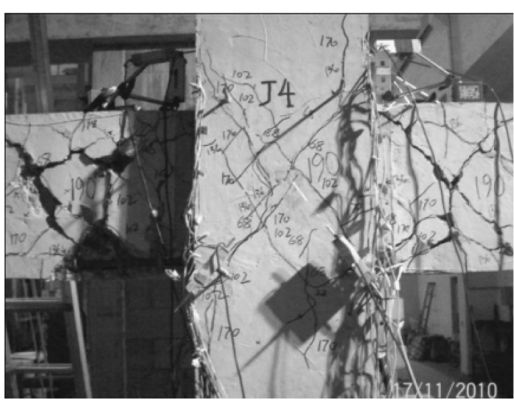

(j) J4, displacement: $190 \mathrm{~mm}$

Fig. 4 Cracks observed at max. displacement

stirrups and additional diagonal bars as discussed earlier. Visual observation of cracks developed in Group II was obviously different or somewhat partial. Cracks developed in J2-1 and J2-3 had similar crack patterns compared to J2-2. The crack patterns of Group II are shown in Fig. 4(e) 
Fig. 4(g) and are explained as follows.

Remarkable crack development happened in $\mathrm{J} 2-1$ as well as in J2-3. The cracks developed diagonal initially, but at higher loading the cracks propagated towards the geometric direction of the diagonal additional bar. In other words, the pattern of the cracks happened to be exactly the same as the arrangement of the additional bars. The assumption made to J2-1 and J2-3, was that, because of joint shear at greater loading, the additional diagonal bars started to yield. However, due to the fact that additional bars were shorter, the strength requirement from the concrete was not sufficient enough. Increasing the length of the additional diagonal bars in this sense, would do greater performance to reinforced concrete beam-column joint.

For specimens without stirrups in the joint, J2-1 and J2-3, the cracks were brittle in the joint after $75 \%$ of shear strength of joint was reached. This exhibited tremendous importance of concrete confinement as recommended by most international codes. Obviously, these joint types are not acceptable in practice both for seismic loading and for gravity loading design.

\section{Group III}

Test frames of Group III have the same reinforcement but the additional bars are arranged along the beam compared to Group II. Specifically, J3-1 is without stirrups but with additional diagonal bars while J3-2 has both, similar to J2-2. Group III was loading with maximum displacement of $190 \mathrm{~mm}$ to failure as shown in Fig. 4(h) Fig. 4(i).

J3-1, behaves the same way as described for J2-1 and J2-3, propagated diagonal cracks and had the regular diagonal shear cracks initially but was severely damaged at increasing displacement storey drift. The cracks were brittle at the joint region after reaching $75 \%$ of shear strength resulting in loose of concrete and spalling off at a faster rate at cyclic loading runs as given in Fig. 4(h). The lost of concrete is definitely because the concrete confinement is absent at the joint region. This exhibited tremendous importance of concrete confinement as recommended by most international code provisions.

For J3-2, the joint exactly behaved the same crack pattern as J2-2 and partially as J1-1. The crack after the maximum displacement of $190 \mathrm{~mm}$ horizontally is shown in Fig. 4(i). The obvious cracks developed after displacement of $36 \mathrm{~mm}$ which was the extreme of elastic stage.

Cracks were of diagonal patterns but centralized at the beams and the joint core region similar to J2-2. There were minor cracks at the intersection between beam and column but were of extreme distance away from the joint region. This showed that, the additional diagonal bars added sufficient strength by few percent to the beam closer to the joint region, which reasonably protected the beamcolumn joint interface. J3-2 has been proven to behave in a ductile manner as beam undergoes plastic hinging earlier than the column. The strength capability showed by this arrangement happened to be slightly higher than that in J1-1.

\section{Group IV}

The cracks developed the same fashion as that of J1-1 and J2-3, and initial diagonal cracks developed when the concrete tensile strength exceeded. The cracks propagated at the beam centralized at a distance away from the joint. The joint region happened to have minor obvious cracks. The cracks at maximum displacement of $190 \mathrm{~mm}$ are shown in Fig. 4(j).

The crack patterns witnessed in J4 reasonably gave clear evidence of safer mechanical failure compared to J1-1. The observed behavior of crack indicated clear cut beam plastic hinging and maximum ductility of the test frame. In the future, further testing with additional diagonal bars in 
this type of joints are of imminent for further understanding of this new proposed design. From the cracks observed, the new design proposal was better than J1-1.

\section{Cracks comparison}

Generally, similar cracks were noticed in all of the specimens, that is, initially flexural cracking followed by inclined shear cracks as the displacement increased. However, specimens with additional bars showed similar initial cracks but crack pattern changed to complex patterns thereafter including flexure, shear and splitting. The additional bars indeed enhanced the joint strength to a certain extend adoptable for seismic design.

For specimens with additional bars and stirrups in the joint region, like J2-2, J3-2 and J4, the additional diagonal bars added certain strength to the beam close to the joint region. The cracks propagated in the beam at a distance away from the joint, and minor obvious cracks developed in the joint region. The specimens behave in a ductile manner as the beam undergoes plastic hinging earlier than the column. Furthermore, the concrete confinement is of tremendous importance to prevent the brittle failure in the joint region.

\subsection{Column shear force versus displacement}

The storey drift was monitored depending on the cracks and the set up procedure throughout the experiment. The stiffness of the column had been fully or partially controlled by the axial load of $200 \mathrm{kN}$ added on top of the column. The axial load also depicted the gravity load in a reinforced concrete moment resisting frame. The hysteretic response of column shear force was recorded throughout each storey drift run, which are given in the following passage. The deformation in the members of the test materials is well defined by the curves in each cyclic loading.

The thick line (Fig. 5) at the centre of the graph shows the single cyclic loading until the test frames started to yield. The curve bigger are those loading done after reaching elastic stage of the test frames. These curves are shown in triple or double (Group I) per cyclic loading. For instance, single loading were done three times, and these curves may fall in the same path or have a gap between them. The gaps between the curves signify the sufficient strength after crack or failure of the test frame at higher displacement loading.

\section{Group I}

Regarding Group I, the gaps between each loading have similar shape and pattern apart from J1-4. The gaps in J1-4 are much bigger than the ones of the rest specimens, that show that in every loading there was a decrease in the strength or the concrete spalled through a single cyclic run. Whereas for J1-1, J1-2 and J1-3, the curves per displacement step have the same path or are close to each other. This shows that even after reaching its ultimate strength, the frame still provided enough strength to the proceeding cycle.

\section{Group II}

Opposite behavior to that of Group I was noticed when graphing the shear against displacement for Group II. Just from the view of curves in each cyclic loading, as discussed for Group I, graph of J2-1 is closely similar to that of J2-3. The curves are not close to each other for each displacement of three times of runs. This shows the failure of test specimens at increasing loads coupled with brittle crushing and spalling of concrete from the test frame. 


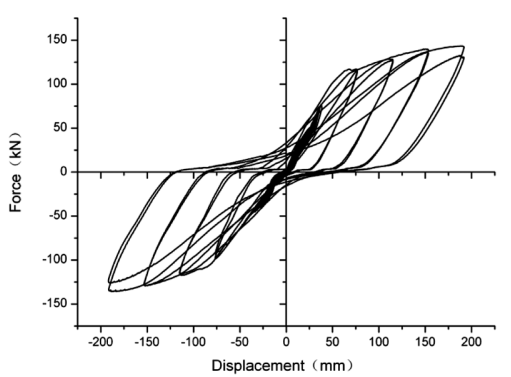

(a) J1-1

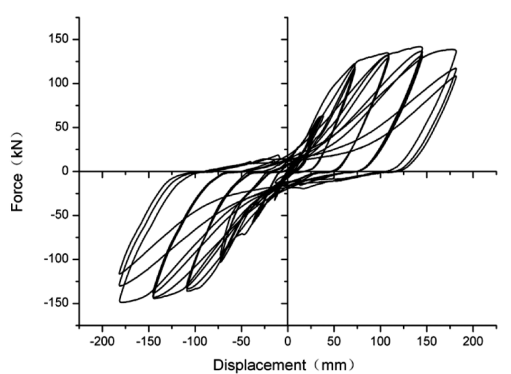

(d) $\mathrm{J} 1-4$

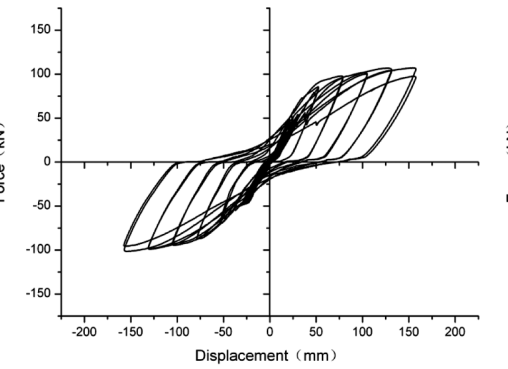

(b) $\mathrm{J} 1-2$

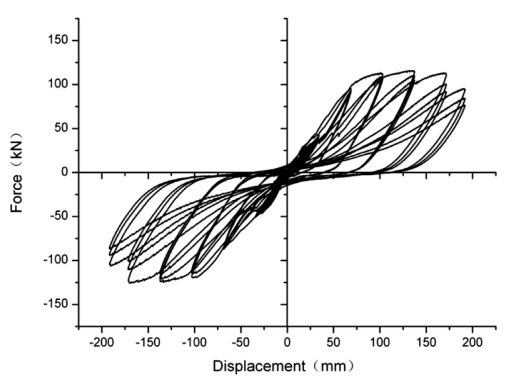

(e) J2-1

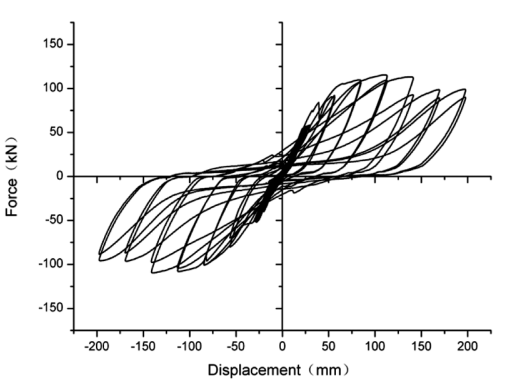

(c) J1-3

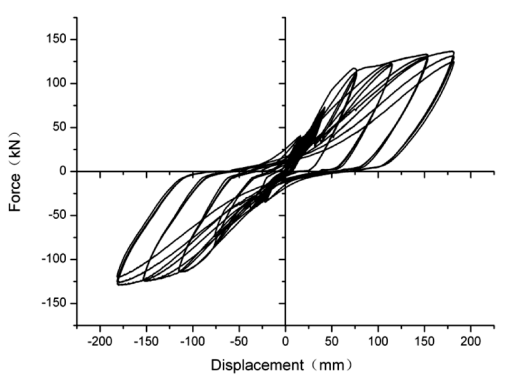

(f) J2-2

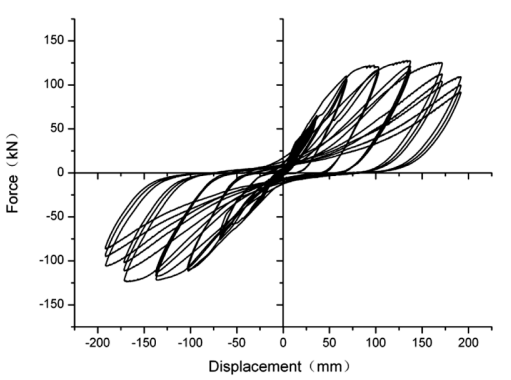

(g) J2-3

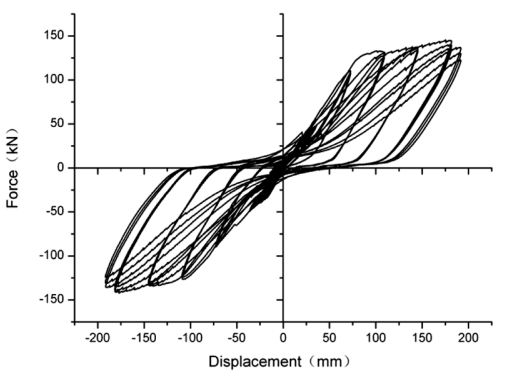

(i) J3-2

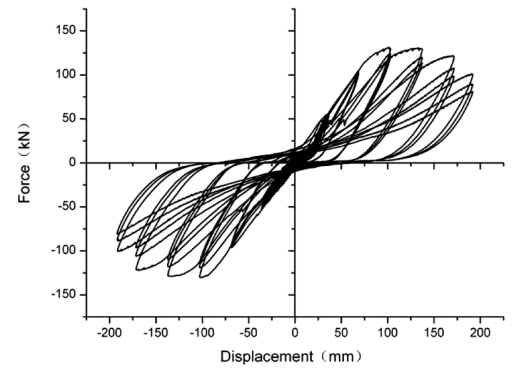

(h) J3-1

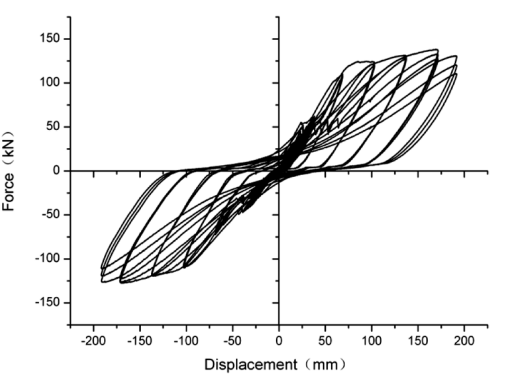

(j) J4

Fig. 5 Shear versus displacement

While in J2-2, at every loading (three runs per displacement), the curves are quite close to each other or almost have the same path at every cyclic reversal. The plotted curves show for themselves that, J2-2, has the highest strength while compared to J2-1 and J2-3. 
Table 5 Test results

\begin{tabular}{cccccc}
\hline \hline $\begin{array}{c}\text { Code Names of the } \\
\text { Specimens }\end{array}$ & $\begin{array}{c}\text { Yield Load } \\
(\mathrm{kN})\end{array}$ & $\begin{array}{c}\text { Yield Displacement } \\
(\mathrm{mm})\end{array}$ & $\begin{array}{c}\text { Maximum Load } \\
(\mathrm{kN})\end{array}$ & $\begin{array}{c}\text { Maximum Displacement } \\
(\mathrm{mm})\end{array}$ & $\begin{array}{c}\text { Ductility } \\
\text { Factor }\end{array}$ \\
\hline J1-1 & 106.70 & 76.75 & 139.53 & 191.75 & 2.50 \\
J1-2 & 81.68 & 51.42 & 104.43 & 157.51 & 3.07 \\
J1-3 & 90.18 & 55.52 & 112.55 & 197.66 & 3.56 \\
J1-4 & 119.34 & 82.28 & 145.39 & 178.64 & 2.17 \\
J2-1 & 84.37 & 74.38 & 120.79 & 184.26 & 2.48 \\
J2-2 & 100.81 & 77.90 & 133.06 & 181.69 & 2.33 \\
J2-3 & 88.58 & 70.35 & 122.19 & 182.80 & 2.60 \\
J3-1 & 89.34 & 79.76 & 131.04 & 176.88 & 2.22 \\
J3-2 & 103.98 & 86.14 & 144.10 & 191.76 & 2.23 \\
J4 & 101.10 & 82.92 & 133.00 & 191.78 & 2.32 \\
\hline
\end{tabular}

\section{Group III}

Having the same idea as explained for Group I and Group II, J3-1 and J3-2, are closely similar to Group II. However, in comparison J3-1 is as weak as that of J2-1 and J2-3 but J3-2 has greater strength than that of J3-1.

Nevertheless, when comparing $\mathrm{J} 2-2$ with $\mathrm{J} 3-2$, the gaps between each cycle are much more different than the other. The curves of J2-2 are much closer than that of J3-2. Thus at this stage, J22 is stronger than the rest as explained above.

\section{Group IV}

The curves of the test specimen are similar to that of J2-2 and J3-2. Meanwhile, J2-2, J3-2 and J4, are recommended to have greater strength. By rephrasing, these test specimens are the ones with additional bars and stirrups within the joint core.

Some of the test results, including the maximum load and displacement, are given in Table 5. Ductility Factor in Table 5 is the ratio of maximum displacement to yield displacement.

\subsection{Comparison on all specimens}

To compare the column shear force against the loading displacement, maximum values were taken for all Groups and were plotted in a single graph as given in Fig. 6. This graph gave clear indication of test frame behavior in its strength, deformation and stiffness capabilities. The ultimate displacement at failure was determined from cross reference using the positive cycles of these envelopes. It is predicated that, failure occurs when column shear strength drops to $80 \%$ after reaching the peak and exceeds displacement of $70 \mathrm{~mm}$.

Corresponding to cyclic hysteresis graphs and collective maximum value in (Figs. 5 \& 6), Group I (J1-2, J1-3 \& J1-4), Group II (J2-1 \& J2-3) and Group III (J3-1), had the least strength and their strength capability decreased at increasing column shear loading. After reaching the peak capacity, the strength of these specimens declined at a steady rate as the number of loading increased. For instance, J1-2 loses its strength after $30 \mathrm{~mm}$ displacement (i.e. $26 \%$ of total loading applied). This is followed by joint specimens with additional bars and stirrups as depicted by J2-2, J3-2 and J4. Though they showed serious cracks and pilling off concrete, the additional bars did provide 


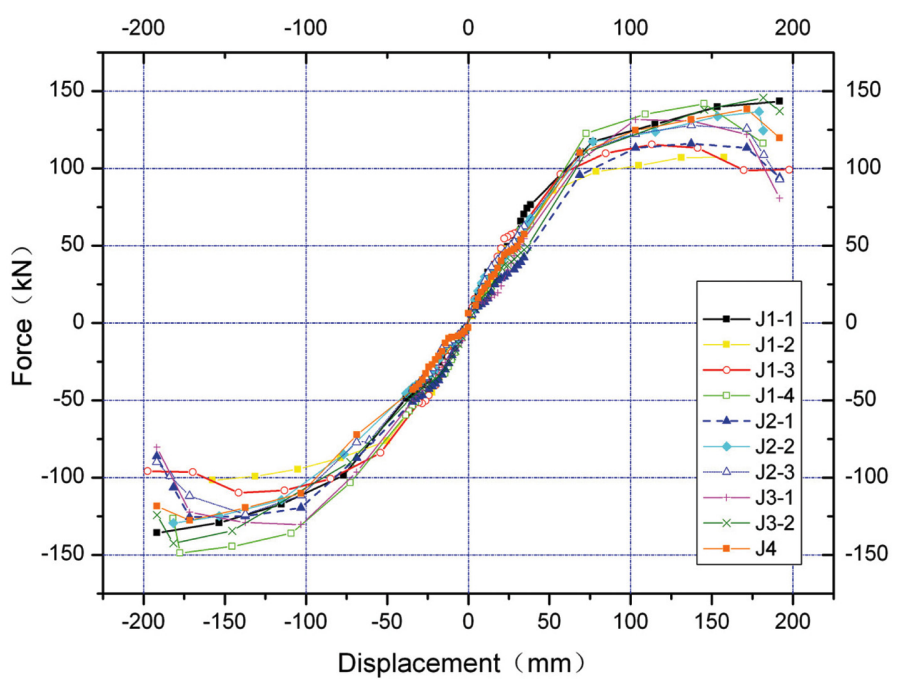

Fig. 6 Max. shear versus displacement

reasonable strength at maximum progressive loadings.

Generally speaking, the conventional design specimens (J1) have sufficient strength, however, at reversal loadings the strength drops rapidly compared to joints with additional bars (i.e. J2-2, J3-2 and J4). J2-2 and J3-2 when compared, exhibit fair strength in their inelastic stage and thus provide enough strength at higher loading cycles in the joint. Hence, specimens with additional bars are an acceptable new design idea that has to be taken heed into seismic design.

\subsection{Joint stiffness versus displacement graph}

The additional axial load from the Hydraulic Jack exerted right at the top of the column gave sufficient stiffness for the test. However, due to reversal loading per displacement and as a result of opening and closing of cracks propagation, the stiffness capacity at the vicinity of the joint decreases. As the cracks increase and decreasing of shear strength of the joint, the entire joint specimen structure weakens. The residual strains of reinforcement accumulated over the load cycles made complex on closing of the opening cracks and caused bond slip at the joint core. It is evident here that, there was reduction in axial and flexural stiffness of the entire specimen.

Referring to Fig. 6, the slope of the straight line joining a peak of each hysteretic loop of column shear force against displacement to the origin in the secant stiffness for that half cycle; the average stiffness obtained for the two half cycles in a hysteretic loop therefore gives the approximate stiffness for that particular cycle. In other words, the secant stiffness was formulated with standard mathematical formula Secant Stiffness $=$ Shear Force/ Displacement $(k=F / \Delta)$. By computation hereto, a graph of stiffness against displacement was plotted as shown in Fig. 7.

Though Fig. 7 gives less evidence because of calculation errors in studying their stiffness behavior, the specimens with additional bars show adequate sustainability throughout loading cycles. For example, the secant stiffness of joint J2-2, J2-3 and J4 obviously is above all other joints at increasing displacement. The axial loading played an important role in controlling the stiffness, however due to shear strength reduction and crack propagation all specimens lost their stiffness 


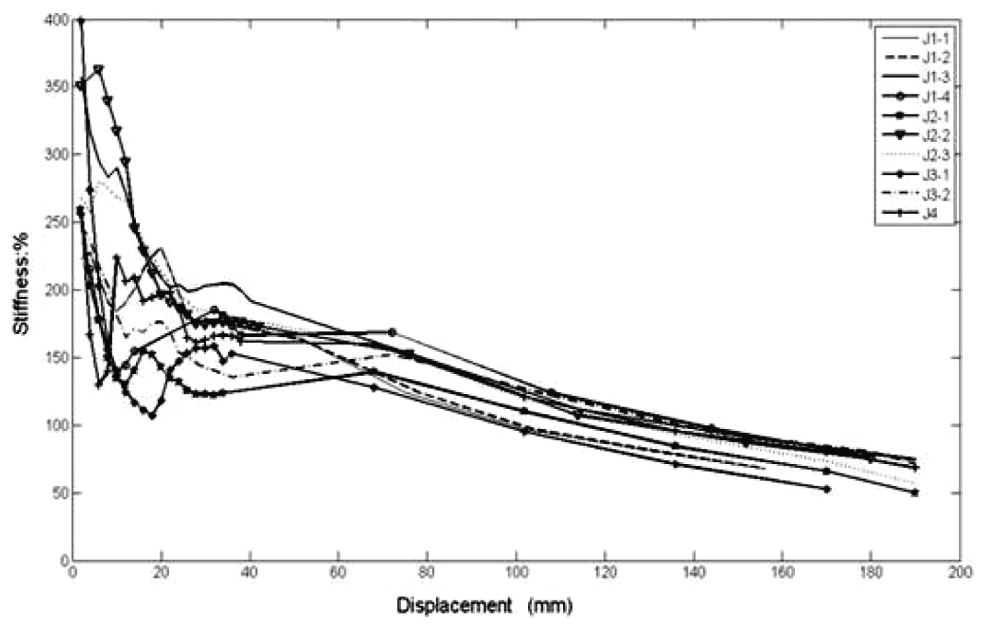

Fig. 7 Stiffness versus displacement

capacity at increasing displacement.

To sum up, the test specimen with additional bars and stirrups did have higher stiffness potentials while compared to the rest of the test specimens. Therefore, the new proposed design of diagonal or straight additional bars can be used in seismic design while compared to conventional joint details as in $\mathrm{J} 1-1$.

\subsection{Joint core distortion}

The joint core deformation and the shear stresses developed within the beam-column joint core are extremely complicated to understand. The interior core of the joint bounded by the longitudinal bars in the beam and column is in fact subject to larger shear stresses and therefore will have more distortion compared with other parts of the test frame. The maximum accumulation of shear at the core believed to develop faster at increasing displacement than shear in the beam or column. This mechanical behavior was obvious in visual observation of crack development as previously explained. For instance, in J2-3, due to higher shear stresses at the core, the additional diagonal bars started to yield in resisting shear stress which is obviously shown on the crack development pattern. Thus, the new design of additional bars did make change in the strength of the joint core.

As the focus of this paper was on the additional bars, the gauge readings mounted on the additional bars and stirrups were taken to study the behavior of joint distortion. In particular, J1-4 was taken from Group I which was compared with the rest of the other test frames. The position of the strain gauges installed is shown in Fig. 8. The maximum strain reading taken from additional bars and transverse reinforcement at the joint region were taken and graphed against displacement less than $80 \mathrm{~mm}$ as given in Fig. 9.

The maximum strain readings also signify the stage of failure for each test frames. As shown by the graph, the higher the strain is, the higher the joint core distortion is throughout loading history.

The use of such readings without suitable definition in the evaluation of joint distortion may lead to underestimation. Nonetheless, it indeed provided sufficient information of the joint shear in understanding the performance of different joint details and configurations under study. It was also noticed that, the joint distortion was affected by the imposed displacements and distribution of 


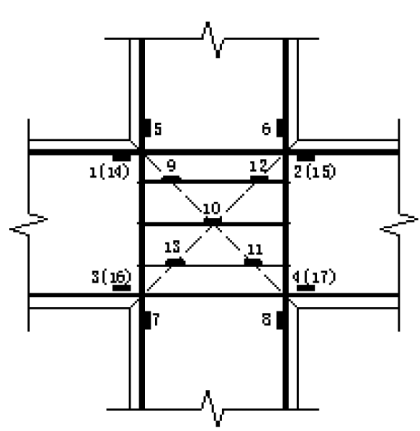

(a) J1-1 J1-4

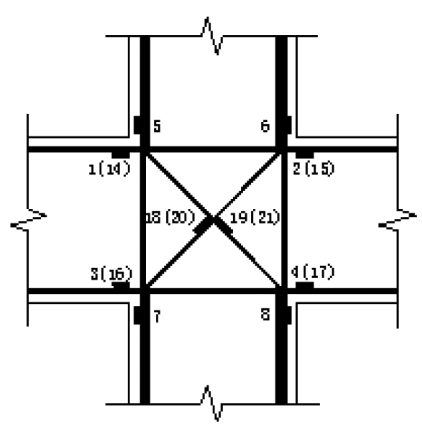

(d) J2-1, J2-3

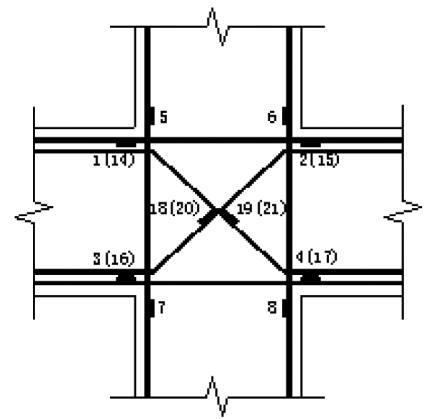

(b) J3-1

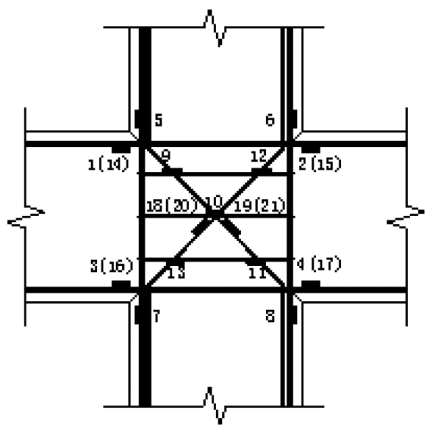

(e) $\mathrm{J} 2-2$

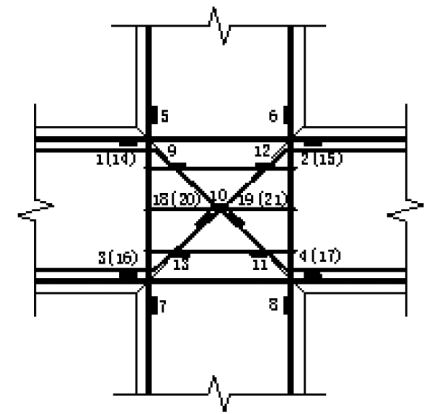

(c) J3-2

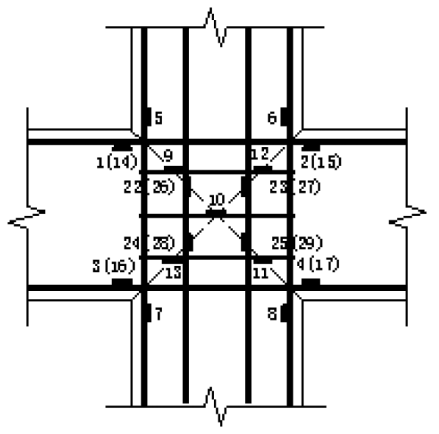

(f) J4

Fig. 8 Installation of strain gauges

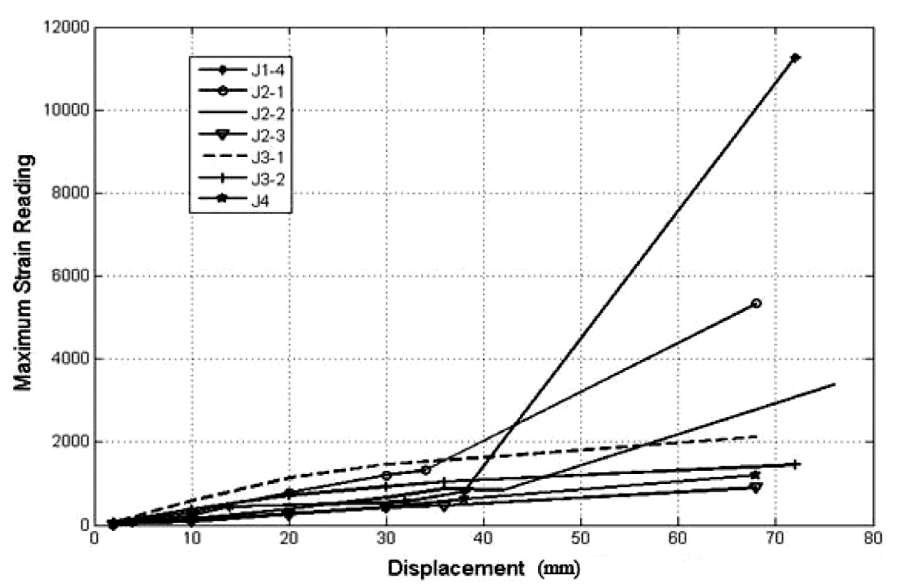

Fig. 9 Max. strain versus displacement

deformation in the entire specimens as well as by actual strength of the specimen types. As given in graph, the specimen with additional bars (Gr.2, Gr.3 and J4) was rather effective in providing sufficient capability in minimizing and/or controlling the crack propagation. In particular, joint distortion of J2-2. J3-2 and J4 was lower than the others.

It is obviously knowledgeable that the rates of displacement in the tensile and compressive 


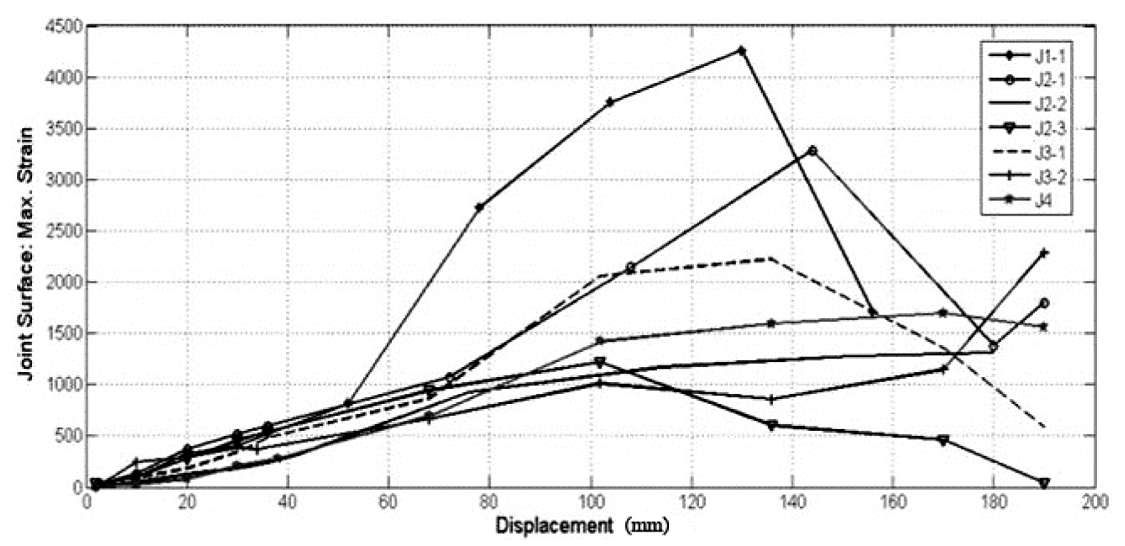

Fig. 10 Max. strain versus displacement

diagonals struts were different. Displacement along the tensile diagonal was often much quicker than that in the compressive diagonal.

\subsection{Crack propagation on joint surface}

The joint surface and beam-column interface cracks were similar cracks as well as different patterns for each test frames during the test. After having close observation throughout loading cycles, it was seen that the cracks extended in length and in depth. An author of an earlier research revealed that the beam-column interface crack could create significant deflection at the beam and amounting to as much as 50\% of the total (Popov 1984).

To study the crack behavior and elongation characteristics, an iron rod was placed through the joint core by which strain gauges were attached. The maximum values for these gauges were taken for the first half and plotted against the displacement as given in Fig. 10. The decline of curves shows the concrete creep and/or concrete opening between loading cycles at higher lateral loadings.

During the test observation, beam-column interface cracks became more obvious with further loading cycles. The specimens with additional bars and stirrups have less cracks and much better control of crack capacity than the others. It can therefore be concluded that the additional bars are much more effective in controlling beam-column interface than conventional joints, that is, Group I, for moderate to medium seismic design practices.

\section{Conclusions}

The concluding remarks here are made in comparison to conventional design practice as specified by Group I, particularly J1-1. All other test specimens were compared with $\mathrm{J} 1-1$ in terms of crack development, joint shear strength, frame stiffness and joint deformation as described earlier. The remarks made through careful analysis are as described below.

(a) With the increase of the ratio of bending moment of column to beam, the plastic hinges are more likely to develop in the beam, and the ductility of the joint improves. Furthermore, the conventional design practice (J1-1) is proven to be accurate by experimenting Group I test specimen frames. 
(b) For specimens without stirrups in the joint, J2-1, J2-3 and J3-1, the cracks were brittle in the joint after reaching $75 \%$ of shear strength of joint. This exhibited tremendous importance of concrete confinement as recommended by most international codes. Obviously, these joint types are not acceptable in practice both for seismic loading and for gravity loading design.

However, additional diagonal bars, like in $\mathrm{J} 2-2$ and $\mathrm{J} 3-2$, prevented cracks at the edges of joint interface between column and beam. Furthermore, these joints have been proven to behave in a ductile manner as beams undergo plastic hinging earlier than the columns. The strength capability showed by this arrangement happened to be slightly higher than that in J1-1.

(c) J4 reasonably gave clear evidence of safer mechanical failure compared to J1-1. The observed behavior of crack indicated clear cut beam plastic hinging and maximum ductility of the test frame. $\mathrm{J} 4$ design proposed has been proven to be reasonable in increasing joint shear strength and distortion capacity of moment resisting frames.

(d) The specimens with additional bars did have sufficient strength after or close to their maximum shear strength. In particular this is seen for J2-2, J3-2 and J4. This is assumed reasonably trustworthy, because the maximum strength designed for the test specimen, were done neglecting the additional bars. Thus, the specimens with additional bars effectively increase the strength capacity at the joint vicinity as well as sufficient development of ductility to the frame members under increasing lateral loading. The mechanism developed in these specimens showed sufficient evidence to suit strong-column weak-beam concept.

(e) While comparing joints described in (e), J4 had much greater strength than that of J2-2 and J3-2. The orientation of additional diagonal bars added strength in favor of members they were oriented to. That is, additional bars along beam (J3-1) added strength towards the beam ends and additional bars along column added strength towards the column. The crack patterns of J2-2 and J32 at the joint developed along the additional bars embedded. However, the crack pattern of J4 behaved the same way as J1-1, but with reasonable increases in joint strength capacity, joint distortion, joint stiffness and yet accurately suits Strong-Column Weak-Beam philosophy. Therefore, additional bars design proposed in this paper is adoptable in seismic design of Beam-Column Joints, particularly $\mathrm{J} 4$.

\section{Acknowledgements}

This work was partially supported by the National Natural Science Foundation of China, Grant No. $90815029,51021140006$.

\section{References}

ACI Committee 318 (2005), 318-05/318R-05: Building code requirements for structural concrete and commentary, American Concrete Institute, Farmington Hills, MI.

ACI Committee 352 (2002), 352R-02: Recommendation for design of beam-column joints in monolithic reinforced concrete structures, American Concrete Institute, Farmington Hills, MI.

Attaalla, S.A. (2004), "General analytical model for normal shear stress of type 2 normal and high strength concrete beam-column joints", ACI Struct. J., 101(1), 65-75.

Au, F.T.K., Huang, K. and Pam, H.J. (2005), "Diagonally-reinforced beam-column joints reinforced under cyclic loading”, Proc. Inst. Civil Eng. Struct. Build., 158(1), 21-40. 
Bindhu, K.R., Jaya, K.P. and Manicka Selvam, V.K. (2008). "Seismic resistance of exterior beam-column joints with non-conventional confinement reinforcement detailing", Struct. Eng. Mech., 30(6), 733-761.

Chalioris, C.E., Favvata, M.J. and Karayannis, C.G. (2008), "Reinforced concrete beam-column joints with crossed inclined bars under cyclic deformations", Earthq. Eng. Struct. D., 37(6), 881-897.

Chalioris, C.E., Karayannis, C.G. and Favvata, M.I. (2007), "Cyclic testing of reinforced concrete beam-columns joints with crossed inclined bars", Proceedings of the 13th Computational Methods and Experimental Measurements (CMEM), 623-632, Prague, Czech Republic.

Cheung, P.C., Paulay, T. and Park, R. (1993), "Behavior of beam column joints in seismically-loaded RC frames", Struct. Eng., 71(8), 129-138.

Eurocode 8 (2003), EN 1998-1:2003, Design provision for earthquake resistant structures. General rulesspecification rules for various materials and elements, European Committee for Standardization, Brussels.

GB 50010-2002, Code for design of concrete structures, Construction Ministry of China.

Ghobarah, A. and Said, A. (2001). "Seismic rehabilitation of beam-column joints using FRP laminates", $J$. Earthq. Eng., 5(1), 113-129.

Hwang, S. and Lee, H. (1999), "Analytical model for predicting shear strengths of exterior reinforced concrete beam-column joints for seismic resistance", ACI Struct. J., 96(5), 846-857.

Hwang, S. and Lee, H. (2000), "Analytical model for predicting shear strengths of interior reinforced concrete beam-column joints for seismic resistance”, ACI Struct. J., 97(1), 35-44.

Karayannis, C.G., Chalioris, C.E. and Sirkelis, G.M. (2008), "Local retrofit of exterior RC beam-column joints using thin RC jackets : an experimental study", Earthq. Eng. Struct. D., 37(5), 727-746.

Karayannis, C.G. and Sirkelis, G.M. (2002), "Effectiveness of RC beam-column connections strengthening using carbon-FRP jackets", Proceedings of the 12th European Conference on Earthquake Engineering, PR549, London, U.K.

Karayannis, C.G. and Sirkelis, G.M. (2008), "Strengthening and rehabilitation of RC beam-column joints using carbon-FRP jacketing and epoxy resin injection", Earthq. Eng. Struct. D., 37(5), 769-790.

Karayannis, C.G., Sirkelis, G.M. and Chalioris, C.E. (2006), "Seismic performance of RC beam-column joints retrofitted using light RC jacket-experimental study", Proceedings of the 1st European Conference on Earthquake Engineering and Seismology, PN 136, Geneva, Switzerland.

Kim, J., LaFave, J.M. and Song, J. (2007). "A new statistical approach for joint shear strength determination of RC beam-column connections subjected to lateral earthquake loading”, Struct. Eng. Mech., 27(4), 439-456.

Leon, R.T. (1990), "Shear strength and hysteretic behavior of interior beam-column joints", ACI Struct. J., 87(1), 3-11.

MacGregor, J.G. (1988), Reinforced concrete mechanics and design, Prentice-Hall, Englewood Cliffs, NJ.

MayField, B., Kong, K.F. and Bennison, A. (1971), "Corner joint details in structural light weight concrete", $A C I$ J. Proc., 68(5), 366-372.

Nawy, E.G. (2005), Reinforcement concrete, a fundamental approach, fifth edition, Prentice-Hall, Englewood Cliffs, NJ.

Nelson, A.H., Darwin, D. and Dolan, C.W. (2004), Design of concrete structure-thirteenth edition, McGraw-Hill, New York.

NZS 3101 (1995), Concrete structures Standard Part 1 and 2, Code and commentary of on the design of concrete structures, New Zealand Standard, New Zealand.

Pam, H.J., Au, F.T.K., Huang, K. and Li, J. (2002), "Behavior of interior beam-column joints reinforced with diagonal steel for moderate seismicity level", Proceedings of the Structural Engineers World Congress WEWC2002, Paper T1-3-d-5, 8pp, Yokohoma, Japan, October 9-12.

Park, R. and Pauley, T. (1975), Reinforced concrete structures, John Wiley and Sons, New York.

Popov, E.P. (1984), "Bond and anchorage of reinforcing bars under cyclic loading", ACI J. Proc., 81(4), $340-349$.

Thermou, G.E. and Elnashai, A.S. (2006). "Seismic retrofit schemes for RC structures and local-global consequences", Prog. Struct. Eng. Mater, 8(1), 1-15.

$C C$ 